\title{
NACH ADORNO: SOBRE LITERATURA
}

\author{
Silvia L. López \\ slopez@carleton.edu
}

Pensar sobre literatura após Adorno, como a palavra nach indica em alemão, significa tanto pensar depois Adorno quanto de acordo com ele. A inevitabilidade do primeiro significado é simplesmente regida pela pilha de detritos que o vento do progresso nos apresentou desde que Adorno escreveu os seus últimos pensamentos sobre estética, há mais de quarenta anos. A escolha deliberada e a consequência do segundo significado decorre de uma compreensão de um regime de arte que continua até hoje a cifrar a linguagem e a forma mediante a fratura de um mundo reificado. O caráter duplo deste compromisso reflete não só uma compreensão particular da história e da produção artística, mas também da sua mediação dialética - em que a Gestalt particular desta última como microcosmo do estado universal da primeira torna-se discernível para nós graças ao poder da reflexão filosófica. Também está vinculado pela historicidade e a política do regime de arte articulados na modernidade.

Antes de continuar, quero tirar do caminho algumas das perguntas imediatas que serão feitas sobre este modo de interpretação, e quero realmente dizer modo de interpretação: os escritos de Adorno não são nem um tropo, um método, um ponto de vista, nem um sistema. ${ }^{1} \mathrm{~A}$

1. Uma explicação contrastante de Jameson e Adorno acerca da dialética pode ser encontrada em Robert Hullot Kentor (2006). 
verdade que ele persegue não é a de uma articulação totalizante entre o modo de produção e a sua reprodução, mas antes um conteúdo de verdade não-proposicional (RICHTER, 2010) que recusa a lógica positiva que foi a marca não só da ciência mas também de grande parte da crítica marxista anterior e parte da contemporânea - de Althusser a Jameson. ${ }^{2}$ A dialética de Adorno não se põe de acordo consigo mesma, nem com a grandiosidade e autossatisfação da verdade tal como é articulada de uma maneira hegeliana progressiva. Para Adorno, o caráter da dialética é negativo, pois ela não oferece nenhuma resolução, nenhuma identidade metaestética entre sujeito e objeto, nenhum agente da história; e o fato de isto não ocorrer não é porque Adorno carece do rigor de Hegel, mas porque ele entende que o particular também faz parte da inverdade do seu momento, como diz no rascunho da introdução à sua Teoria Estética (1998). O pensamento dialético, ele escreve no fragmento 98 da Minima Moralia $_{2}$ "é a tentativa de romper o caráter impositivo da lógica com seus próprios meios" (ADORNO, 2008, p. 147). Consequentemente, não vou apresentar aqui nenhum grande relato sobre o capitalismo e a produção artística, nem tampouco sobre a literatura em particular. A última tentativa titânica de definir a lógica cultural do capitalismo tardio como o pós-modernismo acabou por levar-nos a um cenário em que a encenação paródica pós-moderna descrita acabou revelando-se com cada vez maior clareza como a própria manifestação da forma-mercadoria. Em outras palavras, o mecanismo estilístico e retórico do pós-modernismo alimentava-se da própria indecidibilidade do seu efeito, deixando a nós decidir se a produção cultural do seu momento histórico era uma paródia crítica ou se a estávamos testemunhando como uma paródia da crítica ${ }^{3}$. Basta pensarmos na arte pós-moderna crítica, que, em sua denúncia, recorria às mesmas técnicas da publicidade comercial, borrando a diferença entre a mercadoria e a sua paródia. De maneira dialética, e graças à sua poderosa formulação teórica abrangente, Jameson conjurou nesse momento um aparente deslocamento de paradigma marcado por uma lógica espacial que tinha como característica central a perda de historicidade (JAMESON, 1991). Com ele, veio o fim de uma mediação crítica imanente dos objetos culturais e suas teorias respectivas. Assim que a linguagem do pós-modernismo se tornou a língua franca do mundo acadêmico, os seus sinais de envelhecimento começaram a exigir uma

2. Tal como foi recentemente retomada por diversos autores na última edição do jornal do grupo literário marxista, Mediations (24:2, Primavera, 2009).

3.Uma exposição completa desta posição encontra-se no capítulo "The paradoxes of political art" do livro Dissensus: on politics and aesthetics, de Jacques Rancière (2010). 
nova articulação do momento seguinte do modo de produção, que por sua vez produziu um novo nexo objeto-teoria, desta vez o da globalização e das duas manifestações culturais.

Tomemos por exemplo o fato de que desde estão tornou-se quase impossível sentar-se e escrever qualquer coisa sensata sobre a estética e a globalização sem entrar em uma ordem predefinida de clichês sobre a compressão sem precedentes do tempo e do espaço que se reflete nas interconexões sociais, políticas, econômicas e culturais do mundo de hoje. A teoria literária não ficou imune às pressões para elevar-se à altura do desafio dos discursos sobre a globalização, produzindo, por sua vez diversas tentativas de apreender, compreender e teorizar o seu objeto em sintonia com a ideologia dominante da época. Críticos como Franco Moretti e Pascale Casanova embarcaram em ambiciosos projetos em busca do estabelecimento de novos paradigmas que recriassem um discurso literário globalista e um aparato sistemático que pudesse tornar compreensível o mundo literário. Embora a intenção e as matrizes desse fazer-se-mundo da literatura possam ser diferentes em suas concepções, ambas partilham do mesmo ímpeto crítico-histórico: distanciar-se do discurso dos estudos pós-coloniais e reafirmar modelos de uma compreensão global da literatura que no longo prazo têm um efeito despolitizador, seja pela adoção de um modelo darwiniano empírico da evolução das formas literárias, seja pela reutilização do conceito de autonomia literária, desta vez com os relógios ajustados pelo meridiano de Greenwich. E este momento do reino da globalização será seguido por outro, antes cedo que tarde. O paradigma pós-moderno, o paradigma globalizado, e o que quer que venha a seguir, são todos parte de um processo que insere regime de consenso e de correspondência absoluta, nas práticas artísticas mediante o mesmíssimo dispositivo que forma parte do seu paradigma. Como se pode ver, além da autossatisfação da denominação positiva do mais recente nexo do modo de produção e da sua reprodução cultural, esta maneira de abordar o mapeamento da produção cultural rende muito pouco em termos de uma compreensão teórica crítica do regime de objetos culturais sob o signo do capitalismo moderno.

Como o objetivo central deste texto é tratar da literatura, vamos fixar alguns parâmetros para a nossa discussão. Pelos motivos que já discutimos, uma compreensão teórico-crítica da literatura precisa conservar a primazia do objeto e do seu ponto de vista como premissa fundamental - a Unerlösung, ou inseparabilidade da constituição sujeitoobjeto que é a literatura e do seu reflexo imanente que é a teoria literária - sem, ao mesmo tempo, deixar de conservar também uma compreensão 
histórica fundamental da constelação de relações que reconhecemos como literatura. A compreensão histórica da literatura como fenômeno moderno não significa apenas a emergência da literatura como instituição nas sociedades racionalizadas do modo explicado pelos sociólogos da modernidade, mas uma compreensão muito mais ampla e política da emergência de um novo regime de escrita que se contrapôs a uma antiga modalidade beletrista de representação literária em um momento específico da história.

Ao longo deste ensaio, usarei a ideia de regime da arte proposta por Jacques Racière como: "uma articulação entre três coisas: modos de produção entre os objetos e de interrelação das ações; formas de visibilidade dessas maneiras de fazer; e maneiras de conceitualização ou problematização dessas maneiras de fazer dessas formas de visibilidade" (RANCIÈRE, 20oo, p.16). A ideia de um regime de arte nos permite pensar o nach de Adorno de modo mais compreensível e radical; ela não se limita apenas à maneira como a produção artística moderna opera na modernidade, mas o que ela é o que ela desfaz. O nach de Adorno significa aqui também encontrar uma continuidade com a sua crítica da estética idealista, para a qual a existência da arte ou da literatura não é um produto de um pensamento unificado que nos oferece um conjunto comum de propriedades que venham a definir noções singulares e correspondentes de arte e literatura, sendo elas o produto de um pensamento dissociativo. Isto significa que elas têm sua origem na ruptura que normatiza as belas artes e questionam nosso entendimento acerca do verdadeiro significado da estética desde os primeiros estágios do capitalismo em diante. $\mathrm{O}$ início dessa ruptura foi vivido por Vico e Chardin e rompeu-se

\footnotetext{
aos olhos de Diderot, quando o pintor Chardin misturou em suas paletas, não apenas os tubos de cores para representar um cântaro de olivas, mas também o ar, a água e a luz, para nos fazer sentir a ambientação e sua visibilidade. Rompeu-se em um lugar bem diferente, quando Vico deixou de ler nos epítetos e nas metáforas de Homero o produto de uma arte, para entendê-lo como a linguagem de um pensamento em sua infância. O elo entre a obra e sua interpretação remonta dessa dupla revolução no regime de relações entre o proferível e o sensível (RANCIÈRE, 200o, p. 24).
}

Em outras palavras, a não-identidade da arte consigo mesma é um elemento essencial de um novo regime de arte que rompe com uma estética de representação que nos deu um mundo mediado pela adequação da linguagem e da sensação no capitalismo. Do mesmo modo, a constelação histórica do que chamamos de literatura é relativamente recente e as vicissitudes da transformação de uma forma particular de escrita em 
"literatura" precisam ser entendidas de maneira diferenciada segundo as condições objetivas do regime estético na sua manifestação local. A política da literatura, portanto, terá de ser entendida neste contexto não como uma política de representação, mas antes como uma política que perturba a ordem da representação. A articulação da universalidade do capitalismo, a especificidade da sua articulação local e a emergência de formas culturais nesse contexto resultam em uma tradução do regime estético que ainda define a produção dos seus objetos. Para sermos concretos, podemos dizer com Jacques Rancière que, por exemplo, a Revolução Francesa é essa mudança de paradigma na França; e cito:

\begin{abstract}
A literatura não agiu tanto expressando ideias e vontades quanto exibindo o caráter de uma época de uma sociedade. Nesse contexto, a literatura parecia ao mesmo tempo um novo regime de escrita e outro modo de relacionar-se com a política, apoiada neste princípio: escrever não é impor a própria vontade a outro, à maneira do orador, do sacerdote ou do general, é exibir e decifrar os sintomas de um estado de coisas. É revelar os sinais da história, penetrar como o geólogo nos veios e estratos sob o palco dos oradores e dos políticos os veios e estratos que subjazem às suas fundações (RANCIÈRE, 2010, p.16o).
\end{abstract}

A revolução não apenas causou o colapso de um paradigma representacional particular, como também ocasionou o colapso de um sistema hierárquico de tratamento e o seu regime de significado. Povoou a literatura com as pessoas e a vida da França pós-revolucionária, e assim o pároco não podia mais usar palavras para moralizar a filha do plebeu. E os críticos reacionários tampouco podiam usá-las para moralizar o escritor Flaubert e ensinar-lhe quais assuntos e personagens ele podia escolher. Mas a filha do plebeu, os poetas dos trabalhadores e os trabalhadores militantes estavam todos sujeitos às consequências do novo regime de significado (RANCIÈRE, 2010, p.161).

A linguagem da literatura e o seu sistema de significado não eram mais uma relação entre uma vontade e outra, mas antes uma relação entre palavras e coisas, entre sentido e sentido, entre signos e outros signos. Era a verdade não falsificada das coisas. A crítica faz parte desse mesmo regime de escrita e, como interpretação dos seus signos e sintomas, era imanente ao objeto constituído da literatura. A versão de Rancière sobre a emergência da literatura na França pós-revolucionária é um modo de contar a história, e recomendo a sua leitura; mas podemos decidir contar a história de diversas maneiras, como na linguagem dos românticos de Jena, ou podemos usar a semântica histórica para explicar as condições de possibilidade. A questão é que, seja qual for o nível em que decidamos explicar isto, acabaremos tendo de concentrar-nos 
na dialética de uma certa temporalização histórica para dar conta da emergência da literatura. A especificidade da literatura está diretamente ligada à incursão no tempo que Hegel chamou de história. A história já não ocorre no meio do tempo, mas antes através do tempo. Do tempo à história, da escrita à literatura, a uma categoria de periodização histórica que chamamos de modernidade.

Foi durante o Iluminismo que o termo "modernidade" (Neue Zeit) adquiriu um significado qualitativo com relação à novidade da era e uma transcendência qualitativa de orientação futura. Essa reorientação do termo foi possível depois que a escatologia cristã foi superada e o avanço da ciência, em conjunto com o conhecimento do Novo Mundo, abriu um espaço semântico e, nas décadas imediatamente anteriores a 180o, quando os termos "revolução", "progresso", "desenvolvimento", “crise", "Zeitgeist", "época” e "história” adquiriram determinações temporais que não estavam presentes antes. O tempo deixa de ser o meio no qual todas as histórias procedem; o tempo adquire uma qualidade histórica e tornase uma força histórica e dinâmica em si. ${ }^{4}$

Contudo, a modernidade não se esgota como conceito na semântica histórica, mas tem origem na temporalidade da acumulação de capital e nas suas consequências sociais e políticas para a formação das sociedades capitalistas. As características da matriz histórica da modernidade que a determinam como uma qualidade da vida social marcada pela valorização exclusiva do histórico (em vez do meramente cronológico); a valorização do presente sobre o passado como sua negação e transcendência; a abertura para um futuro indeterminado que só é possível se o presente for concebido como superável e como futuro um relegar do passado; uma tendência à eliminação do próprio presente histórico como transição perpétua entre um passado em constante mutação e um futuro indeterminado - tudo isso aponta para o fato de que a modernidade como categoria de periodização precisa ser entendida não só como ruptura entre períodos, como é claro no caso da Europa, mas antes como uma ruptura da qualidade do próprio tempo histórico.

Essa ruptura é diferenciada por ser a matriz social das sociedades que vivem sob o capitalismo. Se a "historicidade" da literatura europeia está inscrita na partição específica do mundo dado, inaugurado pela Revolução Francesa, em outras partes do mundo a emergência da literatura pode exigir que investiguemos as distintas mediações das suas próprias condições de possibilidade. Neste sentido, podemos pensar que,

4. A descrição clássica deste processo encontra-se em Reinhart Koselleck (2004). 
por exemplo, Machado de Assis marca essa emergência no Brasil, pois com ele acaba um regime representacional particular que é codificado na forma dos seus últimos romances, como foi elucidado brilhantemente por Roberto Schwarz no seu Um mestre na periferia do capitalismo. Machado não apenas encarna as relações sociais contraditórias de um liberalismo imerso nos legados sociais da escravidão, mas constitui-se como a literatura da modernidade contraditória à qual o Brasil aspirava e como uma ruptura na lógica representacional de uma literatura que ainda não nos dava formas de ver, ouvir, e falar o mundo.

E assim podemos prosseguir, detendo-nos em lugares e objetos diferentes, apenas para descobrir que a Dialética do Esclarecimento concebida por Adorno e Horkheimer não é capaz de contar a história dessa emergência de um novo regime de escrita, talvez por ser um elemento essencial da própria ideia do Iluminismo burguês, como sugeriram recentemente Neil Larsen e Norbert Trenkl (cf. LARSEN, 2010). Pode ser que nach Adorno, no seu primeiro significado, não explique a expressão diferencial da modernidade capitalista na sua particularidade histórica, exigindo que olhemos em vez disso para a dialética da modernidade em contextos periféricos, em que o novo regime de escrita chamado literatura oferece diversos níveis de complexidade vis-à-vis da sua própria temporalização histórica.

A hipótese de que aquilo que Trenkl chama de "negatividade fraturada" seja prontamente superado, explicando-se que "a lógica social da relação de valor [...] é aniquilar todo conteúdo e experiência estética" (LARSEN, 2010, p.130) é ao menos problemática. O impulso abrangente da mercadoria descarta todo o esforço de dar conta do regime estético, ou, no nosso caso, da "literatura", como uma constelação de linguagem e significado que produz dissenso na ordem cotidiana de representação consensual.É evidente, tanto a partir da Teoria Estética, deAdorno, quanto das imagens dialéticas que são agora para nós os fragmentos das Minima Moralia, que seu pensamento, em seu caráter tardio nos deixa com uma clara sensação de que não seria nos notáveis momentos especulativos da dialética do esclarecimento que nós deveríamos continuar teorizando a negatividade para compreender a ordem da dissidência.

A maneira como isto re-escreve não só o estético como o político é assunto para outro ensaio. E pode ser que a crise final do capitalismo e da lógica do valor autovalorizante ponha um fim a tudo o que foi discutido acima, porém, nesse meio-tempo, por dar conta dos objetos além do papel funcional que possam ou não ter na lógica final da crise capitalista, isso continuará nach Adorno, desta vez no seu segundo significado, na luta pela interpretação da negação de hoje. 
Na última entrevista que deu ao semanário alemão Der Spiegel em maio de 1969, Adorno, confrontado com a crise política decorrente do Maio de 68 e com o cancelamento das suas conferências sobre pensamento dialético na Universidade de Frankfurt, defendeu a sua atividade teórica diante da revolta estudantil:

Spiegel: Então, o senhor continua vendo o avanço de uma análise das condições societais como o aspecto mais significativo e necessário das suas atividades na república federal?

Adorno: Sim, e imergir-me em fenômenos individuais muito específicos. Não tenho a menor vergonha de dizer bem publicamente que estou trabalhando em um grande livro sobre estética.

Devemos, nach/com Adorno, continuar com o objeto e trabalhar imanentemente para entender a ruptura da ordem consensual que se oferece ao Capital, à Teoria e aos postulados positivos que anunciam o fim da literatura e o fim do mundo.

\section{REFERÊNCIAS BIBLIOGRÁFICAS}

ADORNO, Theodor W. Aesthetic Theory. Trad. Robert Hullot-Kentor (Minneapolis: University of Minnesota Press, 1977).

. Minima Moralia. Trad. Gabriel Cohn (Rio de Janeiro: Azougue, 20o8).

HULLOT-KENTOR, Robert. Suggested reading: Jameson on Adorno, em Things Beyond Resemblance: Collected Essays on Theodore W. Adorno (New York: Columbia University Press, 2006).

JAMESON, Fredric. Postmodernism or the cultural logic of late capitalism (Durham: Duke University Press, 1991).

KOSELLECK, Reinhart. Futures Past: on the semantics of historical time. Trad. Keith Tribe, (Nova York: Columbia University Press, 2004).

LARSEN, Neil, The Idiom of Crisis: On the historical Immanence of language in Adorno, em RICHTER (ed.), 2010.

RANCIÈRE, Jacques. Dissensus: on politics and aesthetics (Londres: Continuum, 2010). . What aesthetics can mean, in From an aesthetic point of view, Peter Osborne (ed.) (London: Serpent's tail, 200o).

RICHTER, Gerhard. Aesthetic Theory and Non-propositional Truth Content, em Language without soil: Adorno and late philosophical modernity, Gerhard Richter (ed.) (Nova York: Fordham University Press, 2010). 